\title{
Los antiguos hornos de vidrio madrileños
}

La artesanía del vidrio tuvo en siglos pasados bastante importancia en la provincia de Madrid. Funcionaron varios hornos dedicados algunos de ellos, como los de Cadalso, Nuevo Baztán y San Martín de Valdeiglesias, a elaborar objetos variados más o menos artísticos, y otros, como los de Valdemaqueda y también ocasionalmente los de San Martín de Valdeiglesias, a fabricar vidrieras para las catedrales de Segovia y Toledo, respectivamente.

También se fabricó vidrio en otras poblaciones madrileñas como Aranjuez, El Escorial y Rascafría (Monasterio del Paular). En estos últimos pueblos se hicieron principalmente vidrieras para sus monasterios.

Las arenas necesarias para obtener el vidrio eran abundantes y de buena calidad en la provincia. Otro importante ingrediente, la barrilla, planta quenopodiácea que crece en terrenos salados y cuyas cenizas sirven para obtener sosa, se adquiría en varios pueblos de la provincia de Toledo como La Guardia, Tembleque, Villacañas, Villafranca de los Caballeros, etc. También se utilizó en muchas ocasiones la barrilla de Alicante y Murcia, de gran calidad, según Danis ${ }^{1}$ :

Tengo por experiencia que la de más fuerza de las de España es la de Ziézar y su tierra, y la de menor verdor la de la huerta de Murcia y tierra de Alicante, y la peor en todo, la de Lillo y toda la de la Mancha.

Se cultivó también barrilla en el pueblo madrileño de Nuevo Baztán.

El barro necesario para fabricar los hornos de vidrio también existía en la provincia de Madrid. El de mayor calidad era el que se obtenía en el arroyo Tórtolas, situado entre San Martín de Valdeiglesias y Cadalso ?:

Para hacer el horno se debe buscar barro de que se tenga experiencia que no derrita al mucho fuego, como es un barro negro que sacan de un arroyo que llaman Tórtolas que está entre San Martín y Cadalso. Segovia.

1 Juan DANIS, Tratado de la fábrica del vidrio, 1689. Archivo de la Catedral de

2 Idem. 
La piedra del cerro de Guisando, próximo a esas poblaciones, era también muy apropiada para construir los hornos.

Para fabricar el vidrio las materias primas, bien molidas, eran calcinadas primeramente para eliminar el agua, y luego mezcladas. La proporción de los componentes de la mezcla variaba según el tipo de vidrio y la técnica empleada por el maestro vidriero. La citada obra de Danis nos permite de nuevo conocer la cantidad de materiales que solían emplearse en esos años en Valdemaqueda, San Martín de Valdeiglesias y en otras poblaciones ${ }^{3}$ :

El vidrio cristal se hace con la guija preparada como se ha dicho y a sesenta libras de guija se le mezclan cuatro libras de salitre muy bien refinado de lo de cañutillo y veinte de albayalde o de minio, uno u otro muy bien molido todo; se juntarán los tres ingredientes, mezclándọlos muy bien y así en polvo se hundirá en los morteros; y este es el cristal que hacen en Francia, Flandes y otras partes y hoy en San Martín y el que se ha labrado en Vista Vella de Aragón.

Para fundir la mezcla se utilizaban crisoles especiales colocados en un horno que permitía calentarlos al rojo blanco (de 1.300 a 1.500 grados).

La obtención de vidrio hueco (frascos, botellas, etc.) se realizaba tomando una porción de pasta fundida en el extremo de un tubo de hierro y colocándola en un molde. Después soplando se adaptaba a las paredes del molde y quedaba hueca en su interior.

El vidrio plano también se obtenía por el método del soplado. La porción de pasta, por medio de un movimiento giratorio del tubo y soplando al mismo tiempo, se convertía en un cilindro hueco que luego era hendido longitudinalmente y extendido sobre un plano.

Para aprovechar el vidrio usado se utilizaba un pequeño molino llamado trámpalo, formado por una piedra con una concavidad en la parte superior sobre la que giraba otra que trituraba el vidrio. Después se fundía y con la masa formada se hacían nuevos objetos.

Para colorear el vidrio se añadía a la mezcla algún tipo dé óxido, según el color que se deseaba obtener. En Cadalso, por ejemplo, sé utilizaba óxido de manganeso lo que daba un aspecto muy peculiar a los vidrios hechos en esa población.

Más difícil era, porque se necesitaban unos conocimientos técnicos especiales, la fabricación de vidrieras. En la provincia de Madrid se obtuvieron algunas de gran calidad, como se ha dicho, en Valdemaqueda, por los maestros Juan Danis y Francisco Herranz, y en San Martín de Valdeiglesias por Francisco Sánchez Martínez.

; Idem. 
De los diversos hornos que funcionaron en siglos pasados en la provincia de Madrid, los que alcanzaron mayor importancia por su producción y calidad fueron los instalados en estas poblaciones:

\section{CADALSO DE LOS VIDRIOS}

Llegaron a fabricarse en este pueblo madrileño los más bellos vidrios de toda Castilla y en su época de apogeo rivalizaron con los de Barcelona e incluso con los venecianos.

Los orígenes de la fabricación del vidrio en esta villa no se conocen pero deben ser muy antiguos, quizá de tiempos de la dominación visigoda.

En un Memorial citado en el Diccionario Geográfico de Tomás López se decía que en 1179 ya funcionaban los hornos cadalseños :

Existen bastantes testimonios literarios que nos hablan de la fama que siempre tuvieron las piezas fabricadas en Cadalso.

En el canto o capítulo decimotercero de la obra literaria del siglo XVI titulada El Crotalón, se comparan los vidrios cadalseños a los venecianos s.

En 1539 Cristóbal de Villalón, en su libro Ingeniosa comparación entre lo antiguo y lo presente, dice textualmente ":

Dexo de decir quanto aya subido en polidez y primor la lavor del vidrio en Génova, Venecia, Barcelona y Cadahalso, donde por la industria de los hombres se contrahazen muchas piedras orientales con toda perfection y las diferencias de los clasificados esmaltes.

En el siglo XVII Méndez Silva dice, refiriéndose a Cadalso: «... labrando en tres hornos finísimo vidrio de hermosas colores y graciosas formas, que puede competir con el veneciano" ${ }^{7}$.

Se siguió fabricando vidrio en Cadalso durante los siglos XVIII, XIX y parte del $\mathrm{XX}$, aunque ya nunca tuvo la calidad y belleza del que se hacía en el XVI y primera mitad del XVII, siglos que constituyeron la época de esplendor. Fue entonces cuando se fabricaron las mejores piezas que tanto

4 Tomás LÓPEZ, Diccionario Geográfico, Manuscrito 7.300 de la Biblioteca Nacional, p. 295.

5 Cristóbal de Villalón, El Crotalón (Madrid: Ediciones Cátedra, 1982), 13." Canto.

6 Cristóbal de VILlalón, Ingeniosa comparación entre lo antiguo y lo presente (Madrid: Sociedad de Bibliófilos Españoles, 1898), p. 181.

7 Rodrigo MÉndez Silva, Población general de España. Sus trofeos, blasones y conquistas beroicas (Madrid, 1645), p. 33. 
admiraron los contemporáneos. Reyes y nobles poseyeron entre sus tesoros preciosos objeto de vidrio de Cadalso.

En el inventario mandado hacer en noviembre de 1503 por la reina Isabel la Católica de todas las joyas y objetos de valor existentes entonces en el Alcázar de Segovia, se cita «una bozina de vidrio de Cadahalso» ${ }^{8}$.

En el inventario del mobiliario, alhajas, ropas, armería y otros efectos de D. Beltrán de la Cueva, duque de Alburquerque, hecho en 1560 y publicado en 1883 por Rodríguez Villa, se mencionan entre los objetos de la despensa ${ }^{9}$ :

- Cinco aguamaniles de vidrio de Cadahalso, deshilados con unos cañones largos para beber en la cama.

- Dos aguamines de vidria.

- Un vidrio boquiancho y una asa azul y otro con tres cañoncitos.

- Una cubilla a manera de redoma para agraz.

- Cinco barriles de vidrio y el uno de vidrio deshilado con sus sospirones.

En este inventario se citan también objetos de vidrio hechos en Alemania, Venecia y Barcelona.

En una relación de todos los objetos de valor existentes en el palacio de El Pardo en 1564 figuran también varias piezas fabricadas en los hornos de Cadalso, entre otras más de Venecia y Barcelona ${ }^{10}$ :

- 17 lámparas de vidrio con cubiertas.

- 6 redomas de vidrio.

- 16 orinales del dicho vidrio de Cadahalso.

Por último, en el inventario de los bienes de $\mathrm{D} .{ }^{2}$ Francisca Ruiz de Castejón, esposa de D. Juan Méndez de Sotomayor, Alcaide de Agreda, figuran, en 1610, objetos fabricados en Cadalso, también con otros venecianos y catalanes ${ }^{11}$.

A finales del siglo XVII se produjo la decadencia de los hornos de Cadalso hasta el punto de que dejaron de trabajar algún tiempo. Hacia 1692 el maestro vidriero Antonio Ovando se encargó de restablecer la fábrica y la de San Martín de Valdeiglesias, por entonces también casi sin uso.

8 M. ZaRco Del VAlle, Datos documentales para la historia del arte español. Inventarios reales (Madrid: Centro de Estudios Históricos, 1916).

9 Luis Pérez Bueno, Vidrio y vidrieras (Barcelona: Artes Decorativas, 1942), p. 73.

10 Juan AInaud de LASARTE, «Cerámica y vidrio», Ars Hispaniae. Historia Universal del Arte Hispano (Madrid: Editorial Plus Ultra, 1952), tomo X, p. 351.

11 Archivo Histórico de Protocolos; Protocolo 1837. 
La labor del maestro fue positiva y consiguió revitalizar los hornos cadalseños que llegaron a fabricar, según Larruga, muchas piezas ${ }^{12}$ :

Se labraban al año 20.000 docenas de piezas que, a dos reales cada docena, importan 40.000 reales. Se consume en la provincia y en Madrid.

Pasados estos años de renacimiento del vidrio cadalseño, se produjo una nueva decandencia en la fabricación. A mediados del siglo xviII las instalaciones de la Granja anularon no sólo a las de Cadalso sino a los restantes hornos castellanos.

Funcionaban en estos años en Cadalso dos hornos que fabricaban objetos de carácter utilitario. Uno de ellos estaba situado dentro de la población, en el barrio de San Antón, y era propiedad de Felipe Frontal, quien lo tenía arrendado a Pedro Gómez Menor, Lorenzo Martín, José Tobar y Antonio Martín. Éstos pagaban por el alquiler 400 reales anuales y trabajaban sólo siete meses. Los beneficios obtenidos por los cuatro socios en el año 1752, después de abonar los jornales de los maestros, oficiales, tomadores, aprendices, etc., fueron en total de 5.791 reales y 29 maravedís. El otro horno estaba edificado en las afueras de la villa, junto a una ermita. Era propiedad de la marquesa de Villena, que lo tenía arrendado también a cuatro socios, Manuel de Arenas, Manuel Martín, Manuel Canoira y Juan Herráez, en la misma cantidad de 400 reales al año, y obtenían parecidos beneficios que los socios del otro horno ${ }^{13}$.

Los maestros vidrieros que trabajaban en ambos hornos eran Manuel de Arenas, Francisco Santillán, Isidro de Rozas y José López de Salas. El jornal de estos maestros era de 8 reales, cantidad superior a la que solía percibir en esa época un maestro artesano medio.

Trabajaban también en los hornos nueve oficiales con un jornal de 6 reales, cuatro tomadores, que ganaban 4 reales diarios, y dos aprendices que percibían 3.

Unos años después el Padre Flórez, en una relación de los viajes que hizo a varias provincias españolas, cita a Cadalso, que visitaba en junio de 1771, mencionando sus dos hornos de vidrio ${ }^{14}$.

En años sucesivos, aunque los productos cadalseños mejoraron de calidad, nunca llegaron de nuevo a la perfección alcanzada siglos antes. En la Ex-

12 Eugenio LaRruga y Boneta, Memorias políticas y económicas sobre los frutos, comercio, fábricas y minas de España (Madrid, 1787-1800), tomo IX, p. 54. Toledo.

13 Catastro de Ensenada: Cadalso de los Vidrios. Archivo Histórico Provincial de

14 Francisco MÉNDEZ, Noticia de la vida y escritos del Padre Fray Henrique Flórez (Madrid, 1780), p. 265. 
posición Universal de Barcelona del año 1888 se puso de manifiesto la decadencia de nuestra vidriería en general, sobre todo comparada con la extranjera, ampliamente representada en dicha Exposición. A propósito de esto dice Alzola y Minondo ${ }^{15}$ :

[...] deplorando todos los amantes del arte español que no se hubiera repuesto aún nuestra industria de su largo período de decadencia en una nación que produjo en Barcelona, Mataró, Almatret, Cadalso y La Granja, aquellas primorosas copas o beyres que no cabe distinguir de las procedentes de Murano.

Desde la segunda década del siglo XIX los hornos de Cadalso pertenecieron a D. Ramón Sáez, y posteriormente a sus hijos hasta también los primeros años de la segunda década del siglo actual.

D. Ramón Sáez, hombre activo y emprendedor, compró la fábrica de vidrio situada en la Corredera (el Arantillo) y posteriormente edificó otro horno de vidrio en la calle de Santa Ana. Los restos de este horno aún existen en un gran patio y también se conserva en el mismo lugar el trámpalo donde se molía el vidrio usado, que se compraba para fundirlo y emplearlo de nuevo.

Después, el horno de la Corredera se abandonó y se construyó otro nuevo. El situado en la calle de Santa Ana quedó sólo dedicado a sustituir al nuevo cuando en él se producía alguna avería.

Durante este último período los hornos de Cadalso seguían fabricando objetos de carácter utilitario, pero muchos de ellos no exentos de belleza.

A principios del siglo actual la fabricación del vidrio continuaba siendo la principal actividad de Cadalso. Dice Ortega Rubio que «la principal industria de la villa es la fabricación del vidrio en dos hornos magníficos» ${ }^{16}$.

En los últimos años de vida de los hornos cadalseños se fabricaban vasos, bombillas, botellas, frascos, frascas para tabernas, tubos para quinqués, etc. También se hacían, en número reducido, bellos pisapapeles que llegaron a alcanzar altos precios y que hoy se guardan como un tesoro en algunas casas de los vecinos de esa población.

La larga duración de los hornos de vidrio de Cadalso hace que las piezas allí fabricadas difieran mucho entre sí, técnica y artísticamente, como consecuencia de las distintas influencias que a lo largo del tiempo recibieron.

En su época de esplendor los vidrios cadalseños, como los de otros lugares españoles, acusaron la influencia veneciana, puesto que los vidrios

15. Pablo Alzola y Minondo, El arte industrial en España (Bilbao, 1892), p. 510.

16 Juan Ortega Rubio, Guía de Madrid y de los pueblos de su provincia (Madrid, 1921), tomo II, p. 238. 
de esa ciudad italiana gozaban de fama mundial. Incluso trabajaron en España bastantes maestros vidrieros venecianos.

Cuando se imitaron en Cadalso los modelos italianos o los franceses, las reproducciones resultaban mucho más toscas en los adornos, y el grosor de las paredes de los objetos era mayor.

Posteriormente las piezas de Cadalso estuvieron influenciadas por las obtenidas en los talleres catalanes y andaluces, sin que presenten por lo tanto unas características propias que permitan clasificarlas de forma clara y definitiva. Un tipo de decoración muy repetida en objetos de fabricación catalana, que consiste en el empleo de líneas onduladas y paralelas de color blanco, se repite frecuentemente en piezas de Cadalso, como podemos ver en varias existentes en el Museo Arqueológico Nacional. La decoración en forma de cadena de color azul que rodea el centro de la pieza y que aparece sobre todo en fruteros hechos en Cadalso, aparece también a menudo en objetos catalanes.

Otra muestra de la imitación de vidrios catalanes por los maestros de Cadalso es la cruz catalana existente en el Museo de Artes Decorativas de Madrid, hecha de cristal transparente y con adornos de color azul entre los brazos, y otra con una decoración muy parecida que se conserva en el Museo Arqueológico Nacional y que se considera elaborada en los talleres de Cadalso.

La pasta de los vidrios andaluces, debido a la gran cantidad de hierro de las arenas empleadas, presenta un color verde característico en tono más o menos oscuro. Pues bien, este color se imitó perfectamente en los hornos de Cadalso, como podemos apreciar en las diferentes jarras, porrones, quinqués, etc., que existen también en el Museo Arqueológico. Otras piezas de Cadalso del mismo Museo presentan un color acaramelado propio del vidrio de Castril (Granada), donde se emplearon arenas de menor cantidad de hierro.

La decoración de las asas de muchos objetos de vidrio andaluces, con una especie de cresta rodeando aquéllas, se repite en modelos cadalseños.

De gran belleza es la jarra de Cadalso que se conserva en el Museo de Artes Decorativas, que imita un tipo de los hornos granadinos. Es de color verde claro con tapa, dos asas y numerosos adornos.

Sí que podemos considerar como típicos de Cadalso diversos fruteros que se guardan en los museos antes citados y otros tres más del Instituto Valencia de Don Juan de Madrid. Son piezas bajas y muy planas, de cristal transparente.

Cuando se abandonaron las diversas influencias, comenzó a labrarse un tipo de vidrio peculiar en Cadalso. Es ligeramente coloreado y contiene unas diminutas burbujas o impurezas no fundidas, por lo que los objetos 
toman un aspecto como de estar cubiertos de polvo. Esto quizá se debiera a la adición de óxido de manganeso utilizado para colorear el vidrio.

Algunas familias de Cadalso conservan piezas de vidrio fabricadas allí en la época de esplendor. Otras muchas poseen objetos variados como vasos, copas, etc., hechas en época tardía y por lo tanto de más valor sentimental que artístico. Los descendientes de D. Ramón Sáez conservaban hace unos años en su domicilio varios objetos fabricados por sus antepasados y en ellos estaban unidos lo utilitario y lo artístico. Destacan varios fanales de cristal transparente, grandes bolas de colores con dibujos de escenas populares, un candelabro de cristal transparente, fruteros, quinqués, dulceras, etc. De extraordinaria belleza son un pequeño joyero decorado con líneas azules y blancas, una dulcera de color azul turquesa y una jofaina con su jarro, también de color azul.

Trabajaron en los hornos de Cadalso numerosos maestros, oficiales y obreros especializados extranjeros que enseñaron a los naturales su arte. Descendientes de algunos de aquellos extranjeros que vivieron en Cadalso son familias actuales que conservan apellidos como Margarit, Meusnier, etc.

Los cadalseños pronto aprendieron a fabricar vidrio de una gran calidad, arte en $e^{\prime}$ que llegaron a ser buenos especialistas. Muchos de ellos, cuando dejaron de funcionar los hornos de su pueblo, se establecieron en otros lugares o se emplearon en otras fábricas españolas e incluso extranjeras.

En agosto de 1838 un maestro vidriero de Cadalso solicitaba del municipio madrileño autorización para establecer una fábrica de vidrio en la capital ${ }^{17}$ :

Josí Martín, avecindado en esta Corte, con todo el respeto debido a V. hace presente que con motivo de las circunstancias políticas ha tenido que cerrar su fábrica de vidrio y cristal establecida en la villa de Cadalso y la ha construido en esta Corte en el sitio llamado de las Vistillas, entrando por la cuesta de los Ciegos y terreno propiedad del Excmo. Sr. Duque del Infantado...

El 29 de septiembre de 1838 se concedía licencia a José Martín para fabricar vidrio imponiéndole algunas condiciones ${ }^{18}$ :

El horno de fundición debe hacerse aislado de todo cerramiento y debe cubrirse - con su gran campana de fábrica de ladrillo sin materia combustible, con su cañón para espeler los humos por encima de las armaduras...

17 Archivo de Villa de Madrid. Secretaría 2-369-18.

18 Archivo de Villa de Madrid. Secretaría 2-369-18. 


\section{NUEVO BAZTÁN}

Una de las grandes realizaciones de Goyeneche en esta villa fue la fábrica de vidrio. Para trabajar en ella utilizó a personal especializado de dos empresas que habían fracasado en la obtención de vidrio de calidad y que fueron la de Tomás del Burgo en 1712 y la de Juan Bautista Pomeraye, en 1718.

En enero de 1720 y por Real Decreto, se concedían a Juan de Goyeneche privilegios y franquicias para establecer esta necesaria industria.

Para edificar el horno y los morteros se empleó tierra refractaria de Tortosa que tenía fama de gran resistencia al fuego. Este horno se hundió y lo mismo ocurrió con otro construido después. Al fin, edificado otro nuevo horno y los morteros, que también habían quedado destruidos, se comenzó a fabricar un vidrio de buena calidad. Según Pérez Bueno, «se labraron en Nuevo Baztán piezas para el servicio de la Real Casa y una vajilla para la casa de S. M. la Reina» ${ }^{19}$.

Destacaba, entre todas las piezas, un vaso que tenía grabados la corona, el toisón y un escudo con las armas de Felipe $V$, que debió formar parte de la vajilla de Isabel de Farnesio.

Se realizaron numerosas experiencias en la fábrica para obtener vidrios de calidad, siendo la más importante la de la fabricación de cristal inglés, para lo que hubo de edificarse un horno especial, sin que se consiguiera el resultado esperado.

Sin embargo, se debieron de obtener vidrios que fueron muy solicitados y que se vendían principalmente en Madrid. Por este motivo los fabricantes extranjeros, que monopolizaban el comercio del vidrio en España y sus colonias, se propusieron arruinar la fábrica de Goyeneche rebajando mucho los precios de sus artículos. Para luchar contra esta competencia Goyeneche organizó la venta de sus productos en su propia casa de la calle de Alcalá de Madrid, en el edificio que posteriormente ocupó la Real Academia de Bellas Artes de San Fernando.

La fábrica se incendió después en tres ocasiones y no debió de ser de forma casual, sino quizá por intrigas comerciales.

La causa de la decadencia de la fábrica fue, sin embargo, la escasez de leña en las proximidades de Nuevo Baztán, lo'que obligó a Goyeneche a abandonar sus hornos y construirlos en el pueblo conquense de Villanueva de Alcorón, donde tampoco tuvo éxito en su empresa, debido ahora a la baja calidad de la pasta, limitándose a elaborar objetos más utilitarios que artísticos.

19 Luis PÉREZ BUENo, op. cit., p. 121. 
Los oficiales de la fábrica de Goyeneche, catalanes unos y otros de Cadalso y San Martín de Valdeiglesias, se dispersaron para luego pasar muchos de ellos a trabajar en la Real Fábrica de La Granja, que se fundó unos años más tarde. Entre los operarios de Nuevo Baztán destacó el catalán Ventura Sit, hombre muy diestro en la fabricación de vidrio, a quien encargó la reina la dirección de los trabajos de La Granja.

\section{SAN LORENZO DE EL ESCORIAL}

En esta población funcionó, desde el último cuarto del siglo XVI, un horno de vidrio con la finalidad principal de fabricar vidrieras para la ornamentación del Monasterio. En él trabajaron varios maestros, casi todos ellos de origen extranjero ${ }^{20}$.

Sabemos que el primer maestro que trabajó allí fue Uldrique, vidriero real y sucesor de los Resén, padre e hijo, quienes habían realizado varias vidrieras para la Corte.

Uldrique o Ulrico Staenheye, alemán, vino a España como componente de la guardia alemana de Felipe II en el año 1566. Por su habilidad, el rey le nombró vidriero real, le dispensó de su actividad militar y le aumentó el sueldo que cobraba en sesenta ducados.

En noviembre de 1574 recibía cierta cantidad de dinero el maestro alemán, importe de tres vidrieras hechas para la escalera principal del Monasterio.

Diez años más tarde seguía Uldrique trabajando en El Escorial ${ }^{21}$ :

En dos días de Agosto se libró a Uldrique, vidriero de Su Majestad, cuatrocientos y doce reales que montan los catorce mil y ocho marevedís que obo de aver, los 396 reales de ellos por 44 días de trabajo que él y un oficial suyo han trabajado en dicha fábrica, haciendo la vidriera para el cuarto de Su Majestad desde doce de Junio pasado de este año hasta dicho día y para el camino de volverse de esta fábrica a Madrid, a razón de 5 reales cada día a Uldrique y 4 por el oficial y los diez y seis reales que pagó de alquiler y costas de dos cabalgaduras en que trajo sus herramientas para trabajar en esta fábrica.

En mayo de 1586 se le abonaban de nuevo 1.478 reales, de ellos 1.200 de «cien cuadros de vidrio cristalino de cuarta en cuadrado», 216 de 18 días de trabajo de Uldrique y dos oficiales y los 62 reales restantes «por

20 Manuel Rico SINOBAS, «Del vidrio y sus artífices en España», Almanaque del Museo de la Industria (Madrid, 1873), pp. 130-178.

21 Archivo del Monasterio de El Escorial, 9-5. 
dos caminos que hizo de Madrid a esta fábrica a trabajar en ella y costa de un carro en que trajeron sus herramientas» ${ }^{22}$.

Al año siguiente seguía el maestro trabajando en el aposento real y en las casas del Bosque de Segovia y el Alcázar de la misma ciudad.

Uldrique murió en 1590 y le sucedió en el cargo de vidriero del rey Antonio Pierres, quien continuó hasta 1600. Tenía asignado un sueldo de 30.000 maravedís además de un jornal de tres reales. En 1593 solicitaba del rey el mismo salario que había cobrado su antecesor Uldrique. Pierres debió de hacer también alguna vidriera para la catedral de Segovia.

El sucesor de Antonio Pierres como vidriero real fue Diego de Ludeque, artífice de vidrios de colores, nombrado para tal cargo por Felipe III en septiembre de 1600. A Ludeque le sucedió en el año 1602 Jorge Babel, quien siguió trabajando para el Monasterio.

En 1607 continuaban allí fabricando vidrieras el capitán Domingo Barrovier, maestro veneciano, y su hijo. Domingo había trabajado antes en Mallorca.

El 28 de marzo de 1607 se firmaba un acuerdo entre Francisco de la Carrera, Procurador Mayor del Monasterio, y los Barrovier, para que se les vendiese a éstos toda la leña necesaria para el horno de vidrio, del pinar de Cuelgamuros ${ }^{23}$ :

[...] y dixeron que son convenidos y concertados en que dicho padre procurador les vende toda la leña de pino que gastaren en dos años en el horno de vidrio que asientan en la dicha villa de El Escorial, contados desde el día que se empezase a poner fuego en el dicho horno, lo qual les da en el término de Campillo a donde dicen Cuelgamuros o en otra parte tan cómoda de monte y carretería a precio cada carro de leña de 40 hasta 50 arrobas de a dos reales y medio pagados de cien a cien carros, como lo fueran trayendo y a condición que la dicha leña se le vende enhiesto en el monte y los dichos vidrieros lo han de cortar, costear y carretear por su cuenta y riesgo y lo que cortaren ha de ser lo que se les señalare por parte del monasterio.

Los bueyes portadores de la leña podían pastar libremente «de la otra parte del Molino de las Armas hacia el dicho monte de Cuelgamuros». Se especificaba también en el contrato que si los Barrovier se fuesen a vivir a otro lugar, a la persona que fuese a cobrarles el importe de la leña le pagarían aquéllos 500 maravedís de salario por día.

22 Archivo del Monasterio de El Escorial, 10-12.

23 Archivo del Monasterio de El Escorial, 15-16. 
En el mismo año una Cédula Real ordenaba la compra de 300 quintales de barrilla de Orihuela que iría destinada al horno de vidrio de El Escorial ${ }^{24}$ :

[...] porque es nuestra voluntad que al capitán Domingo Barrovier, veneciano, que al presente está en el lugar del Escurial labrando vidrieras y vidrios cristalinos para el servicio de nuestras reales casas, se le provean por ésta de 300 quintales de barrilla por cuenta de nuestro Real patrimonio por la orden y forma que abajo se declara $[\ldots]$

La orden iba dirigida a Alonso Ramiro, bayle por Su Majestad y Receptor en la Gobernación del Reino de Valencia, quien envió la barrilla en varios carros para ser entregada al prior del Monasterio.

Poco después Domingo Barrovier se unía en compañía con Oracio Diodati. La unión debió de durar poco tiempo y ambos socios sostuvieron un pleito.

El 15 de septiembre de 1607 tenía lugar un nuevo acuerdo entre el nuevo Procurador del Monasterio y Oracio Diodati ${ }^{25}$ :

[...] de otra parte Oracio Diodati, que ha sucedido en la fábrica y horno de vidrio por cesión y traspaso que hizo el capitán Barrovier de la compañia que entre los dos tenían de dicho horno y todo él con la administración, pertrechos y materiales, está al presente por cuenta y riesgo y cargo de dicho Oracio Diodati y está encargado a pagar todas las deudas que posee el dicho capitán, hasta trece días del presente mes de Septiembre que dicho capitán otorga la dicha cesión $[\ldots]$

Diodati utilizaría la casa y corral con cobertizo donde Domingo y Juan Barrovier fabricaban el vidrio, y que el Monasterio había alquilado a aquellos en 30 ducados anuales. Se comprometía a pagar dos reales y medio por cada carro de leña. En resumen, se obligaba a Diodati a cumplir lo estipulado en el contrato hecho entre el Monasterio y los Barrovier.

Unos meses después, en enero de 1608 , se realizaba un nuevo acuerdo entre el Procurador Fray Francisco de la Carrera y Oracio Diodati por el que aquél le vendía unas 150.000 arrobas de leña de pino del bosque de Cuelgamuros, a cinco maravedís cada arroba y con parecidas condiciones a las estipuladas en marzo del año 1607 con Barrovier.

En ese mismo año fabricó Diodati bastantes vidrieras para la casa real.

Mientras tanto, en abril de 1608, Domingo Barrovier y el también capitán Nicolao Palmota firmaban un acuerdo para crear una compañía a

24 Archivo del Monasterio de El Escorial, 15-14.

25 Archivo del Monasterio de El Escorial, 15-13. 
fin de fundar un horno de vidrio en El Escorial o en otra parte, ante el escribano Jerónimo Fernández y según consta en un documento existente en el Archivo Histórico de Protocolos de Madrid ${ }^{26}$ :

[...] dixeron que tienen tratado y por presente tratan y conciertan de armar compañía en razón de la fábrica de un horno de vidrio para hacerse en El Escorial o en otra parte donde mejor a ambos les pareciere para fabricar vidrieras cristalinas y ordinarias y otros géneros de vidrio ordinarios $[\ldots]$

La compañía había de durar dos años que podían prorrogarse. Barrovier pondría, según el acuerdo, «su persona e industria» para la fabricación de vidrio, y Nicolao Palmota su "persona» y todo el dinero necesario para la construcción del horno e instrumentos. Todo el gasto que supusiese el pleito que mantenía Barrovier con Oracio Diodati lo había de «hacer de su bolsa el dicho capitán y no ha de salir de la dicha compañía». Todos los beneficios y mercedes que Barrovier alcanzase del rey en provecho del horno, serían comunes.

Además de estos maestros vidrieros que trabajaron en El Escorial, otros muchos de Alcantud, Vindel, Recuenco, Cadalso, etc., surtieron al Monasterio de objetos de vidrio como alambiques, redomas, etc., que seguramente allí no se fabricaban.

En el horno de vidrio que funcionó en El Quejigal, localidad próxima a El Escorial y que fue protegido por Felipe II, se hicieron numerosas vidrieras principalmente para la iglesia del Monasterio. Según Rico Sinobas, el propio rey llamó a los maestros vidrieros Francisco y Hernando Espinosa, que gozaban de un gran prestigio, para que dirigieran la fábrica de El Quejigal y labraran en ella los vidrios de color necesarios para el templo ${ }^{27}$.

Por una Real Orden de 18 de marzo de 1565 disponía el rey que se facilitasen a dichos maestros 500 arrobas de barrilla, 12 de colores y 4 de zafre.

A la muerte de los Espinosa dirigió el horno otro maestro apellidado Garcerán, que había trabajado antes en Cataluña.

Hacia 1580 trabajaba también en el Monasterio un maestro de El Quejigal llamado Pedro de Valdivielso, que había labrado ya 460 palmos de vidrieras para la habitación real. Perteneció Valdivielso a una familia de notables vidrieros que trabajaron en las catedrales de Burgos, Huesca y Cuenca.

\footnotetext{
26 Archivo Histórico de Protocolos. Protocolo 2.543.

27 Manuel Rico SinOBAS, op. cit. pp. 130-178.
} 


\section{SAN MaRTín de Valdeiglesias}

En el año 1680 se creó en esta villa una fábrica de vidrio dirigida por Diodonet Lambot, natural de Namur, en Flandes. Este maestro fue contratado por el duque de Villahermosa que era en esos años Gobernador y Capitán General de aquellos estados, y se estableció en San Martín con su familia y varios operarios de su tierra ${ }^{28}$.

Durante unos años la fábrica de San Martín funcionó bien y se obtuvieron buenos vidrios que imitaban a los venecianos.

Diodonet murió en 1683 y le sucedió en la dirección de los trabajos el italiano Santiago Bantoleto, que era hábil en la realización y composición de la masa pero mediocre en las restantes operaciones para la obtención de las piezas como el soplado, modelado, etc. Debido a esto la fábrica de San Martín decayó mucho, dedicándose a elaborar objetos utilitarios como garrafas, vasos, etc. Estos se vendían en Madrid, en un almacén existente en la calle Mayor ${ }^{29}$.

Para evitar esta decadencia intervinieron varios maestros vidrieros de cierta fama como Francisco Laguiola y, sobre todo, Antonio Ovando, quien tampoco pudo hacer nada por revitalizar la fabricación en los hornos de San Martín, aunque, como se ha dicho, sí lo consiguió en los de Cadalso, que también pasaban por un momento difícil tras unos años de esplendor.

A finales del siglo XVII una Real Cédula complementada por un arancel citado por Planell, dio a conocer los precios a que se debían vender los diferentes tipos de objetos de vidrio. Los fabricados en San Martín se valoraban así ${ }^{30}$ :

Cada copa con pie, a 6 cuartos.

Cada vidrio grande de agua, a 7 cuartos.

Cada garrafa doble para enfriar, un real y medio, siendo de azumbre, y subiendo de ahí, a real y cuarto por acumbre y lo mismo respecto a los frascos.

Cada orinal sencillo a 20 maravedís.

Cada vidrio de conserva o «bonete», a 8 maravedís.

Como vemos, en esos años sólo se fabricaban en San Martín objetos destinados al uso doméstico. Sin embargo, más tarde conocerían una nueva época de prosperidad sus hornos al dedicarse a labrar vidrieras para la catedral de Toledo. En ella habían trabajado en siglos anteriores los grandes maestros vidrieros. En el año 1713 fue designado por el Cabildo Francisco

28 Manuel Rico SinOBAS, op. cit., p. 170.

29 Luis PÉREZ BUENo, op. cit., p. 97.

30 Leopoldo Planell, Vidrio: historia, tradición y arte (Barcelona, 1948), tomo I, p. 339 . 
Sánchez Martínez para que restaurase algunos ventanales que estaban deteriorados, con bellas vidrieras que fueron fabricadas en San Martín de Valdeiglesias. En un documento existente en el Archivo de la catedral y citado por Zarco del Valle, se fijaron las condiciones en que debían hacerse los trabajos ${ }^{31}$ :

Estando en la contaduría de la obra y fábrica de esta Santa Iglesia en cuatro de abril del año 1713 el Señor Doctor D. Fernando Merino, Maestre Escuela dignidad canónigo y obrero mayor de ella. Con la ocasión de haber dado su merced el oficio de vidriero de esta dicha Santa Iglesia a Francisco Sánchez Martínez, vecino de esta ciudad que está presente, que ha descubierto el secreto perdido de pintar a fuego en vidrio de que ha dado bastantes muestras y experiencias y para la conservación y reparos de las vidrieras de esta Santa Iglesia y que siempre conste y se sepa la obligación de dicho vidriero en adelante, por ambas partes y por ante mí el presente contador se declararon y previnieron las condiciones siguientes: Primeramente declara que desde luego dicho vidriero se ha de dedicar a ir reparando todas las vidrieras que tiene esta dicha Santa Iglesia con las capillas, salas de cabildos, contadurías, pasadizo y escalera por donde baja a la Iglesia Su Eminencia en la forma que estaban antiguamente y hoy se conservan, con sus pinturas de colores e historias pintadas a fuego y en adelante las ha de conservar y reparar en la misma forma y las que fueron blancas de la misma manera, cuidando de que estén siempre bien.

En 1718 Francisco Sánchez escribió un Tratado del secreto perdido de pintar a fuego las vidrieras, resucitando viejas técnicas.

En 1719 recibía el maestro cierta cantidad por sus trabajos en la catedral ${ }^{32}$ :

En 8 de Noviembre de 1719 se libraron a Francisco Sánchez Martínez, vidriero de esta Santa Iglesia, mil trescientos y cinco reales y 25 maravedís de vellón que valen 44.395 maravedís por los mismos que importan 6 vidrieras las cuatro de San Juachín, Santa Ana y dos escudos de armas reales que están en el claro de encima del órgano nuevo hacia el altar mayor, nuevas enteramente y las otras dos en el mismo sitio, San Ildefonso y el Niño Jesús aderezadas, que entraron en ellas 24 palmos nuevos y en todas 6 nuevas y aderezadas han entrado 97 palmos y medio y se considera cada uno al respecto de 12 reales que es el ajuste que está hecho con dicho vidriero.

Ainaud de Lasarte cita como realizadas por el mismo Francisco Sánchez de 1715 a 1716 «las vidrieras de San Andrés, San Fernando, Santa Inés y San Julián» ${ }^{33}$.

\footnotetext{
31 Manuel Zarco del VAlle, op. cit., tomo II, p. 823.

32 Manuel Zarco del VAlle, op. cit., tomo II, p. 826.

33 Juan Ainaud de LASARTe, op. cit., p. 397.
} 
En 1721 continuaba el maestro trabajando en la catedral de Toledo. Poco después los hornos de vidrio de San Martín dejarían de funcionar, pues no se vuelven a citar en los documentos de la segunda mitad del siglo XVIII.

\section{VALDEMAQUEDA}

Existieron en esta villa madrileña algunos hornos que en el siglo XVI elaboraron productos de buena calidad, principalmente vidrio plano y vasería hueca, que gozaron de merecida fama.

A mediados del siglo XVII los hornos de Valdemaqueda comenzaron a decaer quizá a causa de haber disminuido la calidad del vidrio obtenido.

Unos años después se establecieron en esta población los dos grandes maestros vidrieros Juan Danis y Francisco Herranz, éste también pertiguero de la catedral de Segovia. Ambos fabricantes adquirieron los decadentes hornos de Valdemaqueda en el año 1676 con el fin de fabricar en ellos algunas vidrieras que faltaban en la mencionada catedral, cuyo cabildo contrató en 1674 los servicios de Danis, con el que colaboró Herranz.

La obra a realizar era la elaboración de las vidrieras que faltaban en el crucero y presbiterio como continuación de las realizadas en 1544 en Flandes, Segovia, Medina del Campo y otras de años posteriores. Debía predominar en ellas el color rojo, muy difícil de conseguir, por lo que los dos maestros tuvieron que salvar grandes obstáculos realizando muchas experiencias y utilizando variedad de materiales.

Las vidrieras quedaron terminadas en 1689 y el importe de las mismas fue costeado por el Cabildo y los vecinos de Segovia.

José María Quadrado cita un documento existente en el Archivo Municipal de Segovia, que trataba este asunto ${ }^{34}$ :

Aviéndose gastado hasta el día de hoy 90.000 reales así en 16 vidrieras de las pintadas y 6 de las capillas que están asentadas y materiales que hay para proseguir en gran parte y hornos y experiencias que se han hecho para conseguir lo que tanto se ha deseado y que no se podían derribar los paredones sin tener la iglesia todas las vidrieras y además de esto ser esta obra tan dificultosa que no hay en España y en Flandes quien la haga, sólo Francisco Herranz el pintor que a fuerza de experiencia ha conseguido sacarlas con la perfección y firmeza que se ha experimentado y que puede faltar y quedar esta obra imperfecta y para ello se están debiendo 46.000 reales [...]

34 José María QuAdrado, Recuerdos y bellezas de España: Segovia (Segovia, 1977), pp. $451-452$. 
Juan Danis escribió un Tratado sobre la fábrica del vidrio que se conserva en el Archivo de la Catedral de Segovia y en el que, como hemos visto, expone sus experiencias sobre la fabricación del vidrio que realizó en Valdemaqueda.

También Francisco Herranz recopiló sus experiencias en otro tratado titulado $E l$ modo de hacer vidrieras, que se conserva también en el mismo archivo, unido al manuscrito de Danis.

Herranz cobraba hacia 1679 un salario anual de 26.527 maravedís por su oficio de pertiguero de la catedral.

Además de las vidrieras también debieron de fabricarse en Valdemaqueda otros objetos de vidrio. El mismo arancel citado por Planell fijaba los precios a que debían de venderse por los vidrieros, en la Corte, los objetos de Valdemaqueda y también los de otros lugares ${ }^{35}$ :

Cada vidrio de hechurillas de Barcelona y contrahecho de Venecia y Valdemaqueda, a 14 cuartos.

Copas labradas de Valdemaqueda, a 4 reales.

La alta cotización de algunas piezas de Valdemaqueda, comparables a las de Barcelona y Venecia, nos demuestra que los hornos de esa villa habían vuelto a conquistar su pasado prestigio. Años más tarde debieron dejar de funcionar puesto que no hay referencias de ellos en el siglo XviII.

\section{AlejANDRo PERIS BARRIO}

LÁM. I. Frutero de vidrio de Cadalso. Siglos Xvil-XviII (Museo Arqueológico Nacional).

LÁM. II. Jarra de vidrio de Cadalso. Siglos Xvil-XVIII (Museo Arqueológico Nacional).

3s Leopoldo Planell, op. cit., tomo I, p. 340. 
La artesanía del vidrio tuvo en siglos pasados bastante importancia en la provincia de Madrid. Los principales hornos de vidrio madrileños funcionaron en Cadalso, Nuevo Baztán, S. Lorenzo de El Escorial, S. Martín de Valdeiglesias y Valdemaqueda. En estas dos últimas poblaciones se fabricaron vidrieras para las catedrales de Toledo y Segovia, respectivamente. En S. Lorenzo de El Escorial funcionó un horno con la finalidad principal de obtener vidrieras para la ornamentación del Monasterio. En los hornos de Cadalso se fabricaron piezas de gran valor artístico.

The glass industry was rather important in Madrid during the past centuries, when the main glassworks were established in Cadalso, Nuevo Baztán, San Lorenzo del Escorial, San Martín de Valdeiglesias and Valdemaqueda. Stained glass windows for the Toledo and Segovia cathedrals were made in San Martín and Valdemaqueda respectively, and they were also made for the well-known Benedictine monastery of El Escorial in the factory of San Lorenzo; Cadalso was renowned for its pieces of great artistic value. 


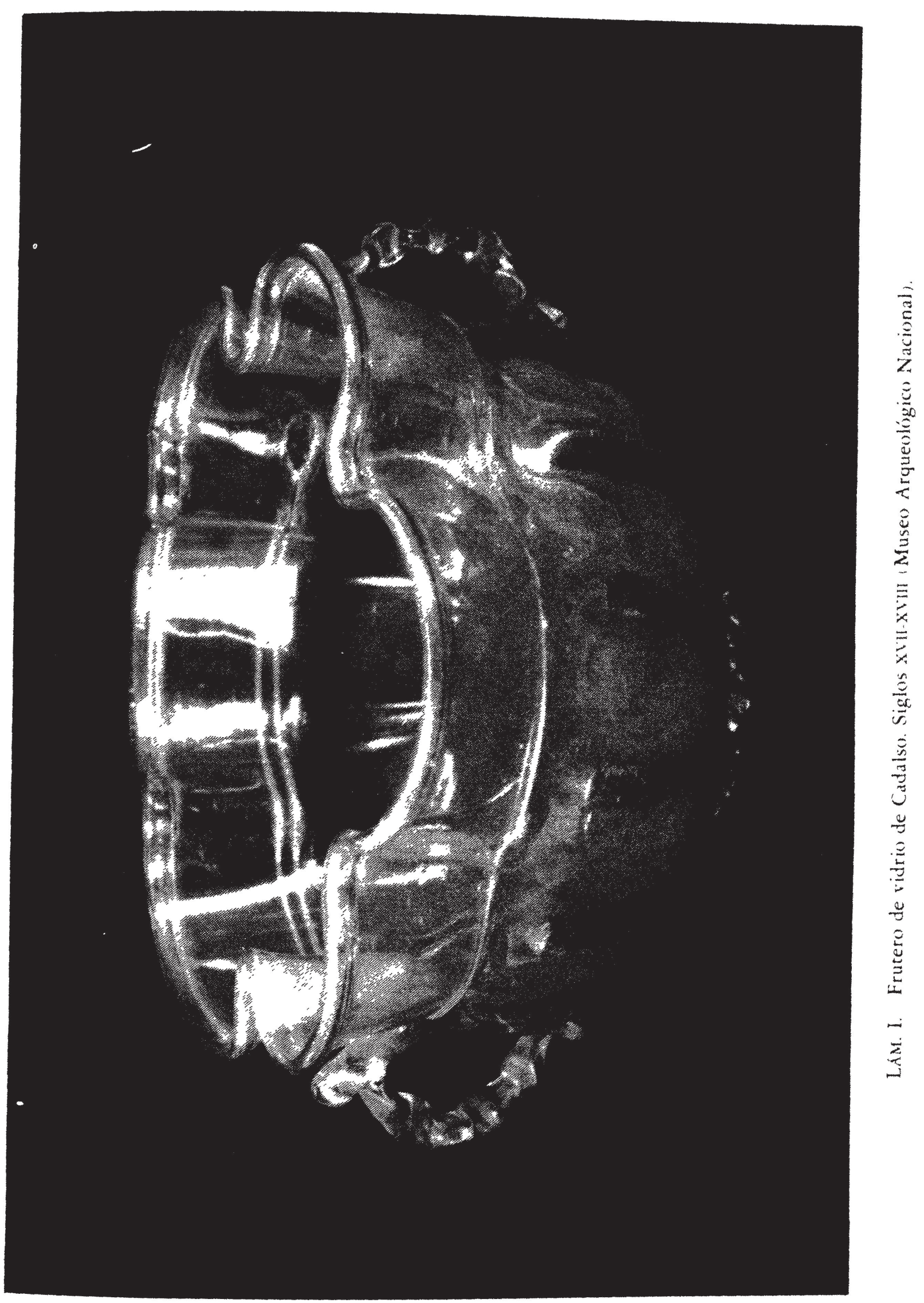

(c) Consejo Superior de Investigaciones Científicas 


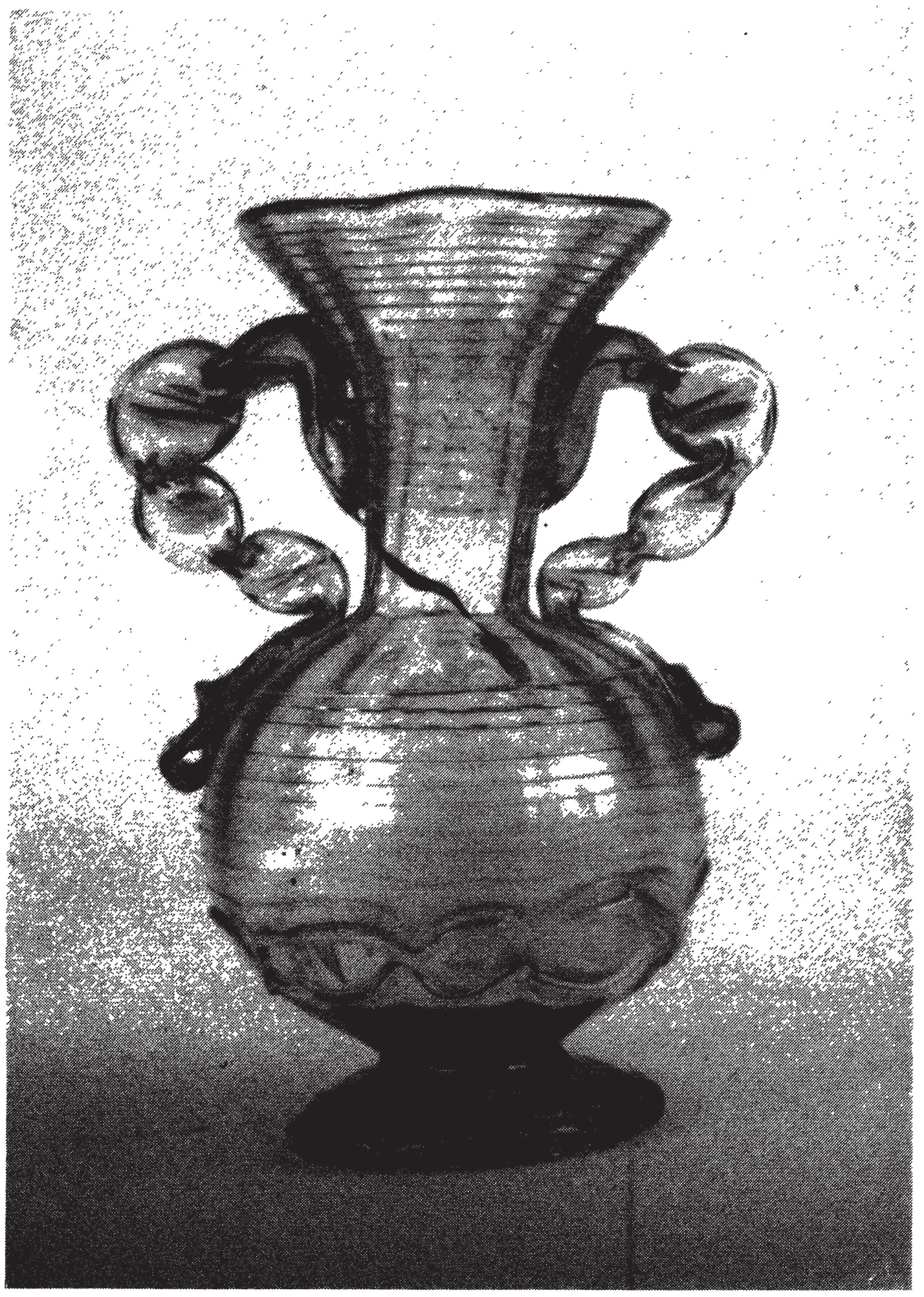

LÁm. II. Jarra de vidrio de Cadalso. Siglos Xvili-XviII (Museo Arqueológico Nacional). 